\title{
Linguistic Profiling and Discrimination in The Witcher 3: Wild Hunt
}

\section{Thor Nordfeld Troelsen $\otimes$}

\section{Introduction}

When first sitting down to play a new game, exposition is sorely needed for a player to understand the game world they will be inhabiting. Today, the primary delivery device for this is that of recorded dialogue and voice-over. With voices being presented to us, real-world dialects and associations can be established, which could lead us to infer or draw conclusions and judge them on this basis. This "ability to identify an individual's race or ethnicity on the basis of voice alone is a phenomenon that has been referred to as linguistic profiling" (Lippi-Green 2012, 122), which can lead to discrimination as shown by John Baugh in his studies about the housing market in the US (Purnell et al. 1999). The consequence of this discrimination can be terrible for those subjected to the stereotypes elicited by their voice, but could stereotyping in media such as video games also be useful? This article explores the possible usefulness for linguistic profiling within video games, through the lens of CD Projekt Red's The Witcher 3: Wild Hunt (2015), and the unfortunate linguistic discrimination which it might elicit. To do this, the world of the Witcher will be introduced, after which a more thorough explanation of the phenomenon of linguistic profiling will be presented. Following this will be a look at the dialects and accents in The Witcher 3 and why something like linguistic profiling might be important in characterization. This leads into a categorization of most of the varieties of British English that are presented within the game, and how these might be discriminatory. Finally, a short discussion of these findings and the implications of linguistic discrimination will be discussed before the conclusion of this article.

\section{The world of The Witcher}

The Witcher 3: Wild Hunt (TW3) is a fantasy RPG (role-playing game) from 2015 by Polish developer CD Projekt Red, based on the fantasy Witcher saga of books by Polish author Andrzej Sapkowski. The Polish aspect is important, because for this article it will be the English translation and adaptation of 
the game that will be discussed. In the game players take control of Geralt of Rivia, a monster slayer for hire known as a witcher, who Sapkowski's book series revolves around. Witchers are humans who through mutations have gained superhuman strength and reflexes. They wander the Continent slaying monsters for coin, staying aloof from politics and wars as they seek neutrality in all things to protect their guild's integrity. In TW 3 Geralt embarks on a dangerous journey to find the child of prophecy, Ciri, his daughter by choice. Ciri possesses immense abilities and is therefore pursued by a spectral cavalcade of riders from another world, known as the Wild Hunt. Yet, it is not them alone that might hinder Geralt as war engulfs the Continent at the onset of the story. The Witcher world is one of great

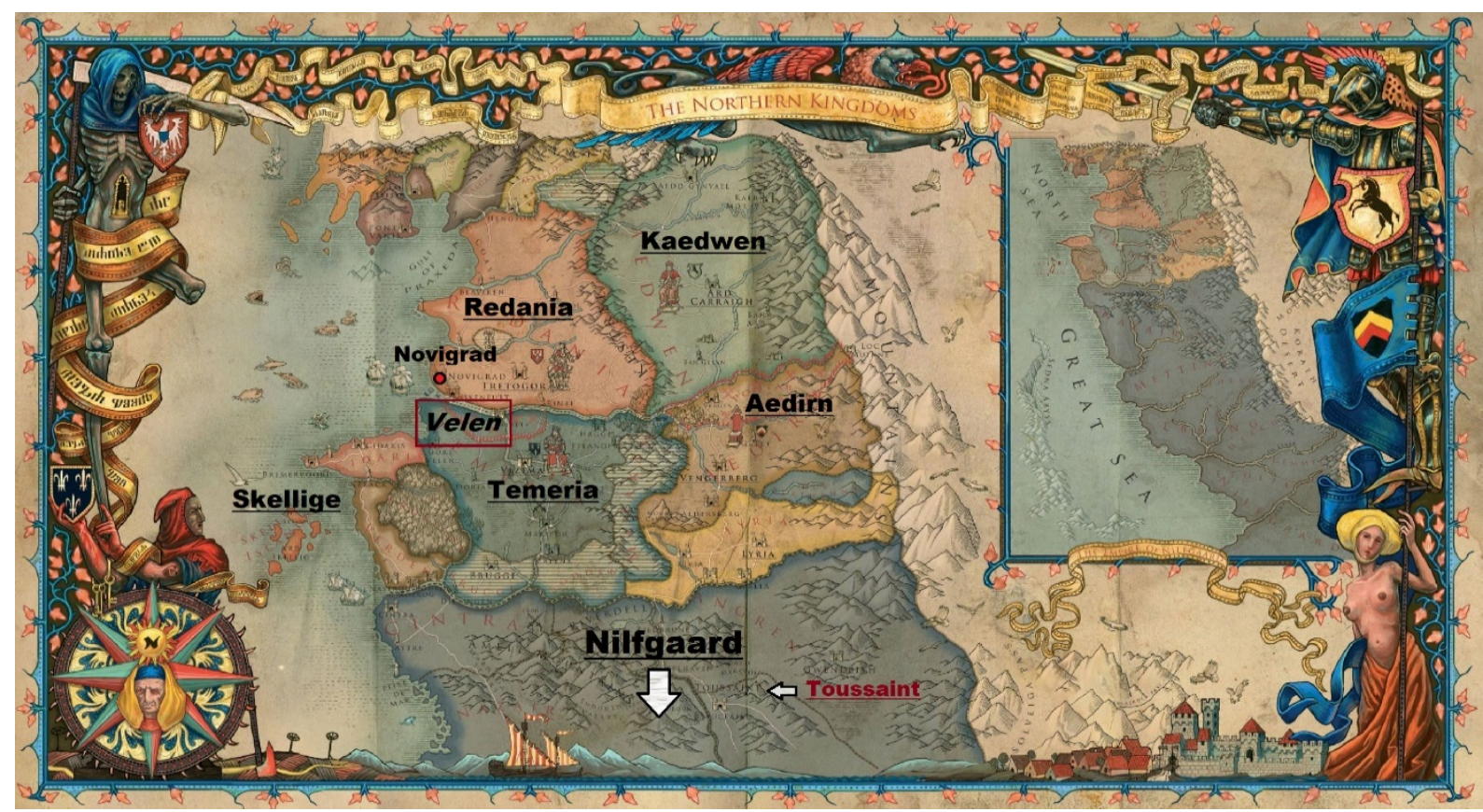

Figure 1: The Northern Kingdoms (Velen has been marked by a box and Novigrad with a dot to show their extension). (C) CD PROJEKT S.A.

conflict; centuries before the saga begins, human settlers came to the Continent, and replaced the Elder races, making Dwarves and Elves second-rate citizens who had to adapt to a world where they were no longer the dominant species. Meanwhile, more recent times have seen the growth and expansion of the Nilfgaardian Empire, which like the Roman Empire has conquered and made provinces of immense swaths of lands, their conquest having led them to the very doorsteps of the fragmented Northern Kingdoms. 


\section{Linguistic profiling}

Linguistic profiling is the phenomenon wherein prejudice is directed at a speaker solely based on the way they speak. John Baugh first wrote on the subject, and details that "linguistic profiling was discovered [...] when fair housing advocates happened to notice that many of the minority speakers who were seeking to obtain housing by telephone were systematically denied opportunities to visit properties or obtain rental applications" (Baugh 2016, 363). His studies were specifically focused on dialects and accents within America, with a focus on the black community, but the term has a wide appeal, as this sort of profiling and possible discrimination is more common than one might think. How we speak is integral to our identity (Hellström 2019, 1), as it denotes which region or area we come from. Therefore, accents and dialects denote and distinguish us, but they might also be cause for discrimination and stereotypes. One of the prime examples of this is a study done by Coupland and Bishop (2007), where accents of different English-speaking regions have been ranked in terms of attractiveness and prestige through surveys done by participants of different age groups and different English-speaking regions; "The survey shows that overt accents which are not tied to a specific region, such as RP, are ranked high on both the prestige scale and the attractiveness scale, and covert accents that are exclusively or partially exclusively spoken within one region are placed much lower on the scale" (Hellström 2019, 5). The mere process of ranking accents is discriminatory in the first place, because it creates an Us vs. Them mentality, or a standard vs. non-standard distinction, as can be seen in the fact that variations like Queen's English and Standard English score high on both prestige and attractiveness ranked between 34 different accents and dialects. On the other hand, the Birmingham English is ranked lowest on both counts (Coupland and Bishop 2007, 79). This just goes to show how people might be discriminated against based only on the linguistic features in their speech.

This linguistic profiling of dialects has long been used in this way, and in modern media the manipulation of language variation is as relevant as ever. In her master thesis, Lien details the accents of Game of Thrones (HBO, 2011-2019) critically, and states that " $[\mathrm{t}]$ he speech of characters is not merely of communicative significance; it is also a way of quickly implying the background of the speaker, regionally as well as socially" (Lien 2016, 1). In fantasy media such as Game of Thrones, as well as in $T W 3$, we are dealing with fantastical settings that may not have easily distinguishable people. For the consumer to be able to tell folk apart, appropriated accents and dialects become a useful tool to distinguish and denote which folk might come from which region or kingdom. The problem then arises when real-world dialects are chosen for a kingdom or region, and their real-world associations or stereotypes follow them into the work of fiction; "Dialect does not merely reveal the geographical 
area you are from; people often hold a range of other associations with it as well. To illustrate, people tend to view speakers with working-class accents as less well educated" (Lien 2016, 5). Sometimes these stereotypes follow dialects, but other times they might not, and dialects might have been chosen by the producers deliberately for a variety of reasons. Linguistic profiling is not the problem in itself, as this is only a phenomenon of recognizing a dialect or an accent; rather, it is the discrimination that might infer from such recognition, which is problematic. As stated in an article on these very terms, Nour pointed out that "[i]t's not a problem if someone can infer someone's race or national origin from a phone call. The problem begins when one's inherent biases toward a certain group become the reason they don't call back" (Nour 2019). This linguistic profiling is what this article will examine further.

\section{Dialects and accents in The Witcher 3}

Part of what immerses us in a game, and is the focus of this article, is the immersive capability of voice acting in video games. The meaning of immersion here is defined as the deep mental involvement in a fiction, in which you, although knowing it is fictious, suspend your disbelief for its duration to enjoy it more thoroughly. For this immersion not to be broken, the dialects and accents portrayed in your game must come across as authentic: "Authenticity has often been considered a significant criterion for the success of accent representation." (Lien 2016, 42). Here the problem of possibly offensive stereotypes in conjunction with certain dialects appear, such as was exemplified by Lippi-Green with Disney's representation of a Jewish stereotype in "Three Little Pigs" (1933), which gained major backlash for the company. Comparably, how has CD Projekt Red dealt with this in their game? In the English version of the video game, British English was chosen for the most part as the variety of English spoken by the inhabitants of the Continent. As "The Witcher is a very European game, like in content and flavor" (O’Dwyer 2017, 5:38-5:45) British English makes sense for the general accent of the people of the Witcher, as the game is medieval and European in its setting, and appropriate English accents might feel more authentic for such a world, even though they are not speaking in the Middle English of the Medieval period (Lien 2016, 17).

The Northern Kingdoms are a sprawling place, yet to look at a Kaedweni or a Temerian, there are no physical characteristics or mannerisms that might distinguish them from one another. For the most part, the Witcher world is distinctly Caucasian, and here distinct dialects and accents appear as a much-needed tool for characterization and distinction of the different cultures, regions and social levels people inhabit. In doing so, the developers have taken special care in choosing which dialects 
and accents should be utilized (O'Dwyer 2017, 18:37-18:43) and have distributed them accordingly. While this might be considered as part of linguistic profiling, as we will discuss further, I would argue that it also helps settle the player as they can clearly hear people speaking differently, making it clear that this is a diverse world, with internal rules and logic, even linguistical ones. Some players might recognize the various accents and dialects, while some might not. Some players will be able to tell that some peasant speech includes h-dropping as well as other factors, and that this was not done by aristocrats. If the stereotypes some accents or dialects are often associated with are unknown to the players of the game, it might be hard to draw any meaningful conclusion on whether or not this is part of linguistic discrimination, as it might not be apparent to the players. Besides, no real parody or harmful intention seems to be behind the dialects, which would argue for the fact that this is just part of a strategy to make the world believable to the player. Pugacz-Muraszkiewicz, English Adaptation Director of $T W^{3}$, states in an interview with Danny O'Dwyer from Noclip that for exposition not to be too obvious to players, certain theatrical ruses must be used: "Those ruses include ... extreme characterization ... hiding things in dialect and accents and hiding things behind emotion" (O'Dwyer 2017, 10:14-10:25). All of this is done to "distinguish them against ... the mass of NPCs that populate our world" (ibid, 10:54-11:01). The focus of the developers seems to have been with this creed in mind: distinction. The dialects of the Northern Kingdoms overall do not seem to be based upon popular stereotypes about certain British dialects. Broadly speaking in Temeria, they speak Southern English, in Redania they speak Northern English, in Kaedwen they speak Southern Irish (ibid, 2:082:11), and in Aedirn they speak Welsh (ibid, 19:12-19:20). There are no caricatured or stereotypical behavior expressed in any of these kingdoms that would make them more likely and fitting to have been portrayed with a certain dialect. This distribution instead seems to have been primarily concerned with establishing dialects and accents for the different kingdoms to make them distinct, and recognizable for players.

\section{Analysis of Witcher dialects}

The following section will detail a variety of the different dialects and accents which are in $T W 3$, but it is not exhaustive. We will examine the pairing of Temeria and Redania's dialects, Velen and Novigrad, then Skellige, leading us on to the non-humans of the North (Elves and Dwarves) and some of the uses of RP for nobles and sorceresses, continuing with Nilfgaard and finally finishing up with Geralt's accent. 
The dialects of the two neighboring kingdoms, Redania and Temeria have distinct Northern and Southern English characteristics, so for this pair these are the features which will be explored. One of the Redanians in Witcher 3, Dijkstra, a former spymaster, speaks with a distinct Northern accent, which is exemplified by his absence of BATH broadening, where his pronunciation of baths have the same vowel as TRAP with an [a] instead of [æ] (Wells 2013). Additionally, he uses the slang term nowt in saying: "Whoreson's got nowt to do with the casino", a term which is a distinctly Northern, especially used in Yorkshire (Castelow, n.d.), which points to this as Dijkstra's specific regional dialect, although he does speak with clear pronunciation, making his words easily understandable. Meanwhile, the Temerian accent is Southern in its features, where the main share of Temerians in $T W 3$ have either Cockney or West Country accents, which will be detailed in the next section. The conclusions we can draw from this comparison is that the Temeria and Redania's dialects serve to represent two different people within the game and does not delve into stereotypes associated with Northerners or Southerners. Here its function is merely to help tell two kingdoms apart through dialect, as neither is depicted as either solely good or bad nations.

Yet, when venturing further into Temeria, the player comes across Velen, where a more pronounced Southern rural accent is displayed: "[W] went so deeply into the country that we went deep into ... a West Country accent for the Velenese" (O’Dwyer 2017, 18:58-19:05). One of the most prominent features that show Velenese speaking with a West Country accent is their rhoticity (Lien 2016, 20). In words like shelter the rhotic / $r /$ is emphasized in the end, which is done by the peasants of Velen. Another feature "is the dropping of the voiceless glottal fricative /h/. This is a feature that can be tracked geographically and one that can be found in West Country English. The dropping of the /h/ is illustrated ... in the word 'Hills', which sounds the word as [Ilz] instead" (Mattsson 2018, 19). Besides, the informal tone they speak in, where them gets shortened to ' $\mathrm{em}$ also helps characterize the accent but could also be considered to help in embedding a stereotype about the West Country accent, as the Velenese are portrayed as rural simple folk. Moving from the country to the biggest city in the North, Pugacz-Muraszkiewicz details that "Novigrad struck us as a metropolis, enough of a melting pot that it would become London" (O’Dwyer 2017, 19:52-19:57). The most prominent features of Novigrad, I would argue, is the working-class accent of London, known as Cockney, which is spoken by the criminal characters of Novigrad and by urban acquaintances of Geralt from Temeria. One of these is the Temerian spymaster, Thaler, whose use of the [In] ending, in words such as ploughin' and bein' shows his working-class dialect (Wells 2013). The same h-dropping as in the West Country example is also apparent with Thaler and the criminals of Novigrad, where head becomes 'ead in their 
pronunciation. Another is the TH-fronting and DH-fronting, where [f, v] is used instead of the standard $[\theta, \chi]$ in words such as thing (Wells 2013), where Thaler pronounces the th more like an initial [f]. Counter to the previous pairing the linguistic profiling is more apparent here, as the accents selected seem to reflect that West Country equals rural, uneducated farmers, while Cockney-speakers are criminals. While these accents must have been chosen because they seemed fitting, in terms of urban and rural environs in England, they also run the risk of reinforcing stereotypes.

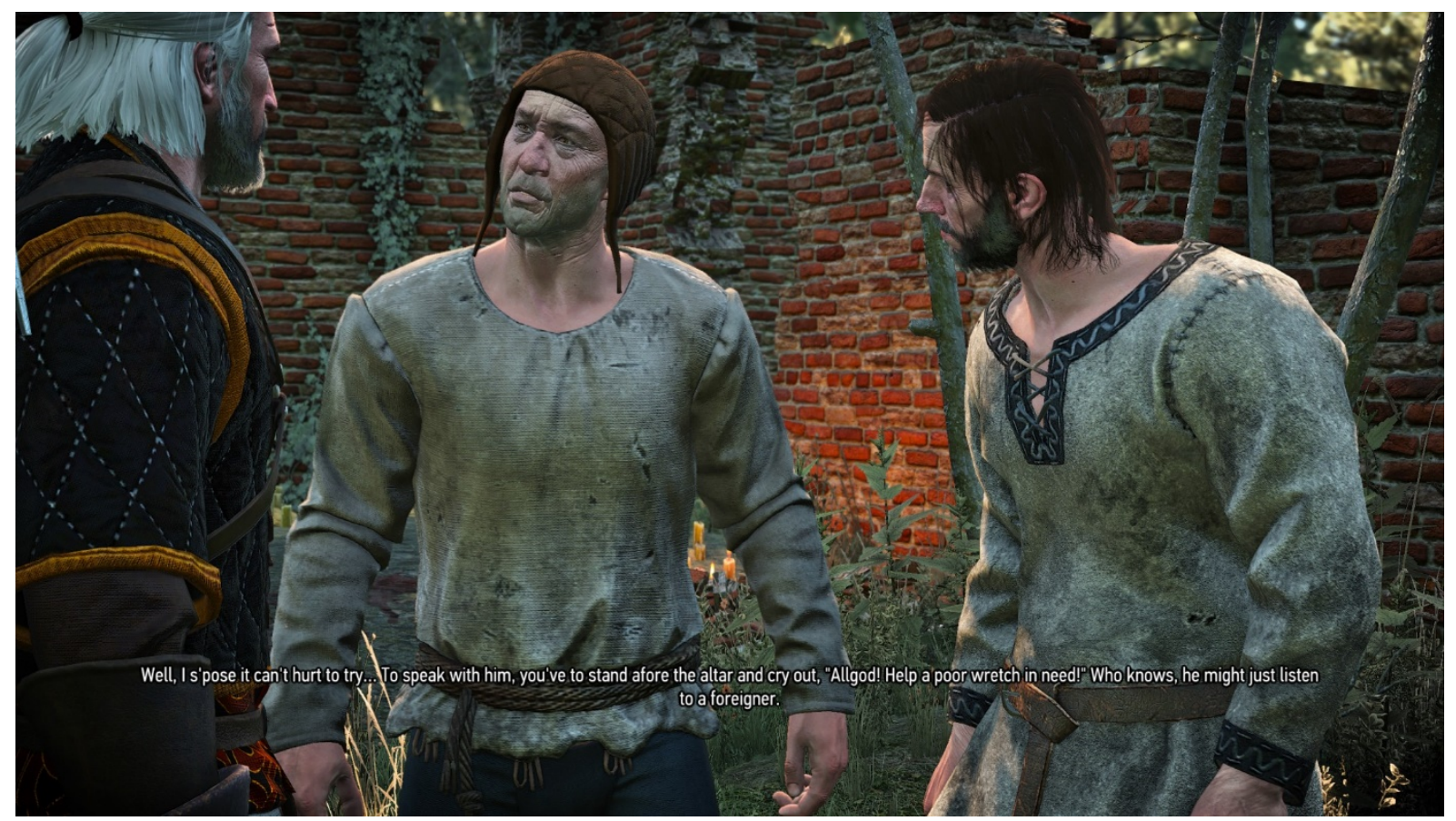

Figure 2: Peasants from Velen with Geralt (left) C CD PROJEKT S.A

When one ventures out to sea from the Northern Kingdoms, the archipelago of Skellige can be found, where savage raiders divided into clans reside. Sapkowski's characterization of them are equal parts Gaelic and Scandinavian, as can be seen in their culture, where the goddess Freya figures heavily, they go to sea in longboats, await Ragh nar Roog, and red hair is a typical genetic feature of the raiders. Besides, "Skellig(e) derives from the Irish (Gaeilge) "Sceilg", which can be translated into "Rock" or "Cliff". There are also Skellig Islands in the Atlantic Ocean, part of Ireland" (Witcher Wiki, n.d.). For these reasons, Northern Irish was ultimately chosen for the Skelligan dialect, as Southern Irish had already been established for Kaedwen in The Witcher 2, and while Norwegian with English subtitles was considered, it was dropped as it would have been too unintelligible for players (O'Dwyer 2017, 19:5820:51). Here it is the cultural background and the many Gaelic loanwords that the author originally 
used that makes Northern Irish a good choice and also provides an accent that is different enough, but still familiar to the varieties of English spoken in the Northern Kingdoms. Its characteristics are its rhotic/r/, which is more like the West Country dialect, rather than the tapped or rolled /r/ of Scottish English (Mattsson 2018, 8). Another feature is its distinct intonation pattern, with "a very noticeable tendency to raise the pitch towards the end of an utterance, even if the speaker is not asking a question" (Robinson 2019). The stereotypes elicited through these people is more closely related to Vikings, and I would therefore say that Skelligers are not profiled as heavily based upon their language as some of the other examples.

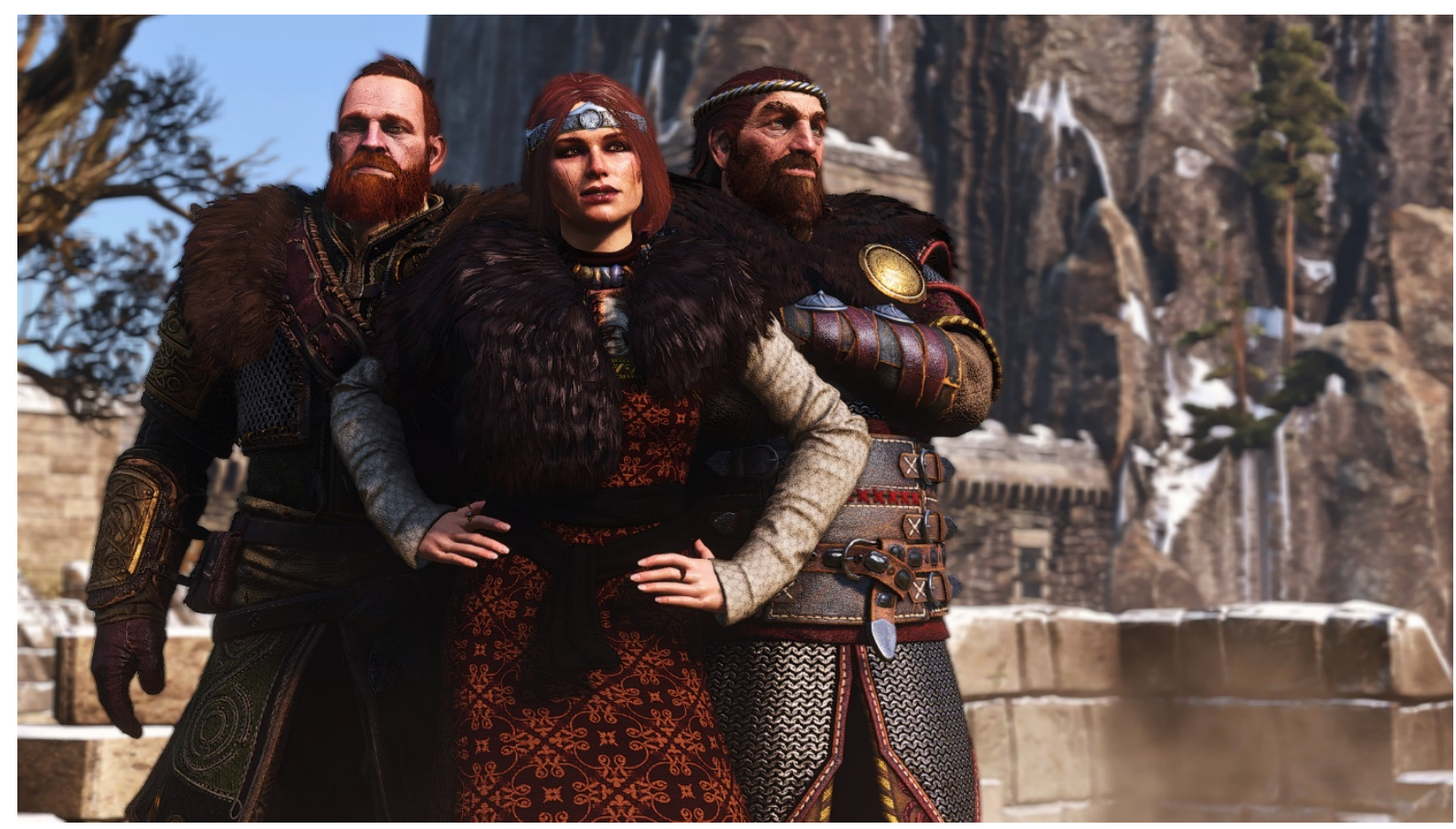

Figure 3: Skelligers C CD PROJEKT S.A.

A popular stereotype that is apparent in the fantasy genre that the game follows is that all Dwarves speak with a Scottish accent, exemplified by such phrases as "ah dinnae ken" which is Scottish slang for “I don't know” (Campbell-Howes 2019). Besides, their rhotic / r/ is very strong, and has a tapped or rolled /r/ (Bratteli 2011, 71) and the "main verb have does not require do-support" (Mattsson 2018, 7). What is interesting about Dwarves, is that the stereotype that they use Scottish accents seems cemented in pop culture, although its origin is unknown. As Bratteli discusses in his MA thesis, the fantasy Dwarf which saw its modern interpretation 


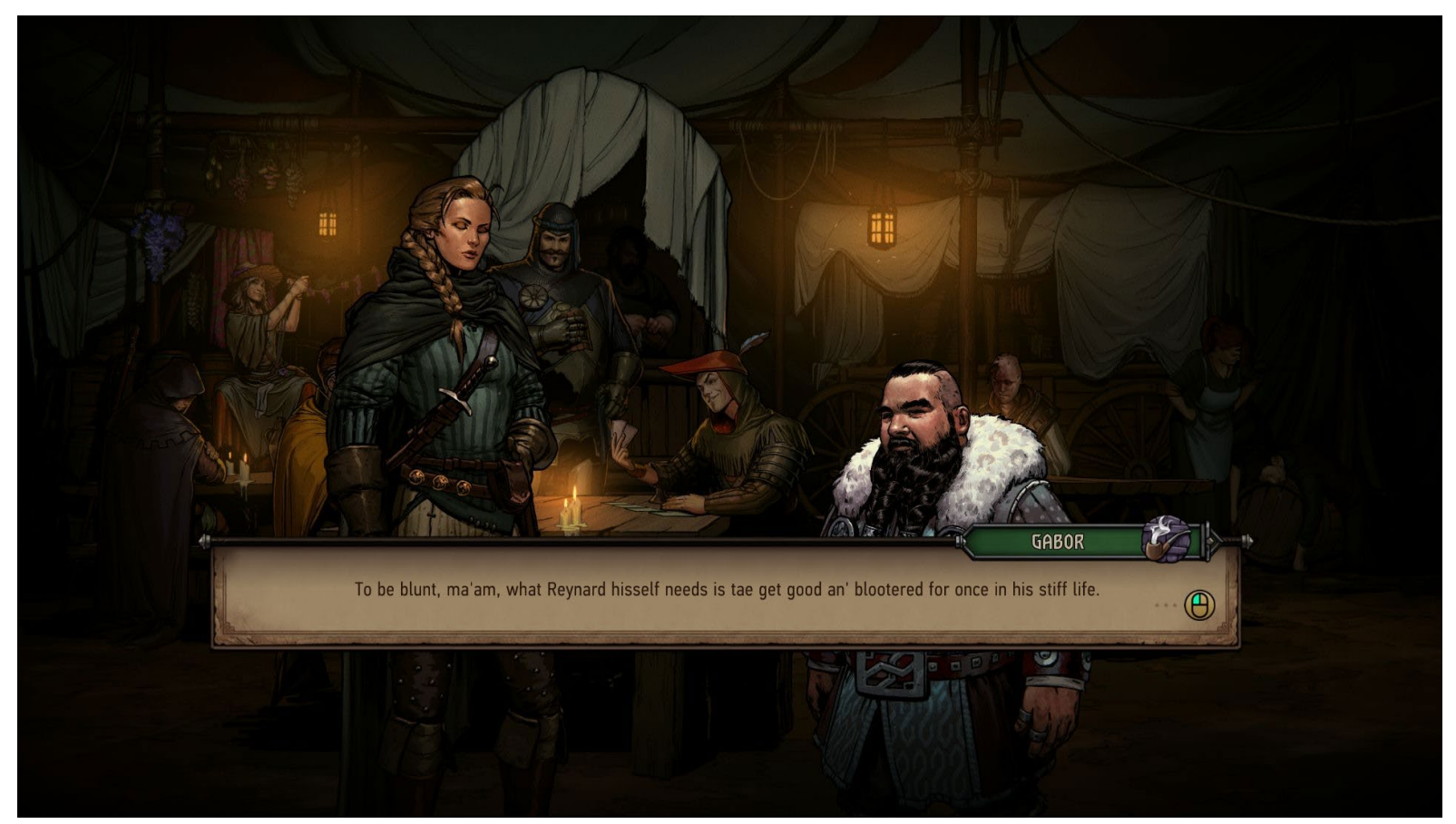

Figure 4: Dwarf from Thronebreaker: The Witcher Tales (C) CD PROJEKT S.A.

through the work of Tolkien, originally had a language based on Hebrew but has in recent times often been depicted with a Scottish accent; "The Scottish, then, seem bound against dwarves, who are usually mountainfolk, fond of beer, often temperamental, and fond of mining and especially gold" (Bratteli 2011, 35). The common selection of the Scottish accent then seems to derive from the fact that in a British setting, Scottish stereotypes seem to fit the Dwarf best, and if this is the reason, I would agree that this holds true to the criticism of stereotyping figuring into a video game like $T W 3$.

Another popular stereotype concerns fantasy races such as Elves speaking in RP, which also holds true for $T W 3$, but it is not limited to them alone, as the Kings of the North, aristocrats, Sorceresses and the Nilfgaardian Imperator Emhyr var Emreis do as well. This accent is often associated with refined and intellectual characters (Baugh 2003, 164), but is also seen in the vein of the "well-established practice of rendering evil geniuses as Brits" (Lippi-Green 2012, 122). RP therefore also helps denote villainous characters in $T W 3$. The main villain in the game is Eredin, the King of the Wild Hunt, who is an elf from another dimension, and accordingly he is characterized by his Received Pronunciation. His "accent is mainly distinguished by his use of rounded /a:/ in the words last and afterwards in 'Any last Words' - ['eni la:st w3:dz]; The use of non-rhotic distribution of /r/, as seen in:

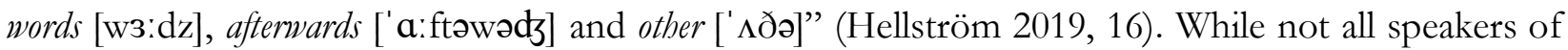
$\mathrm{RP}$ in $\mathrm{TW} 3$ are distinctly evil, when it comes to Kings and sorceresses most of them are morally gray 
in character. Another example is the casting of Charles Dance in the role of Emhyr var Emreis, whose vocal talents here bear a striking resemblance to his appearance as Tywin Lannister in Game of Thrones, where his distinct RP accent is prevalent. While Nilfgaardian, Emhyr was raised in the Northern Kingdoms after being exiled, which helps to explain why he speaks with an RP accent, as the general Nilfgaardian dialect can be categorized as Dutch. Much like the Elves, one of the Elder Races, and the sorceresses of the North, intelligence and prestige exude from his being, which makes the choice of this accent plausible. Besides, the level of authentic representation also makes one of the most prestigious British accents a good choice for an accent that nobles in a feudal society would speak.

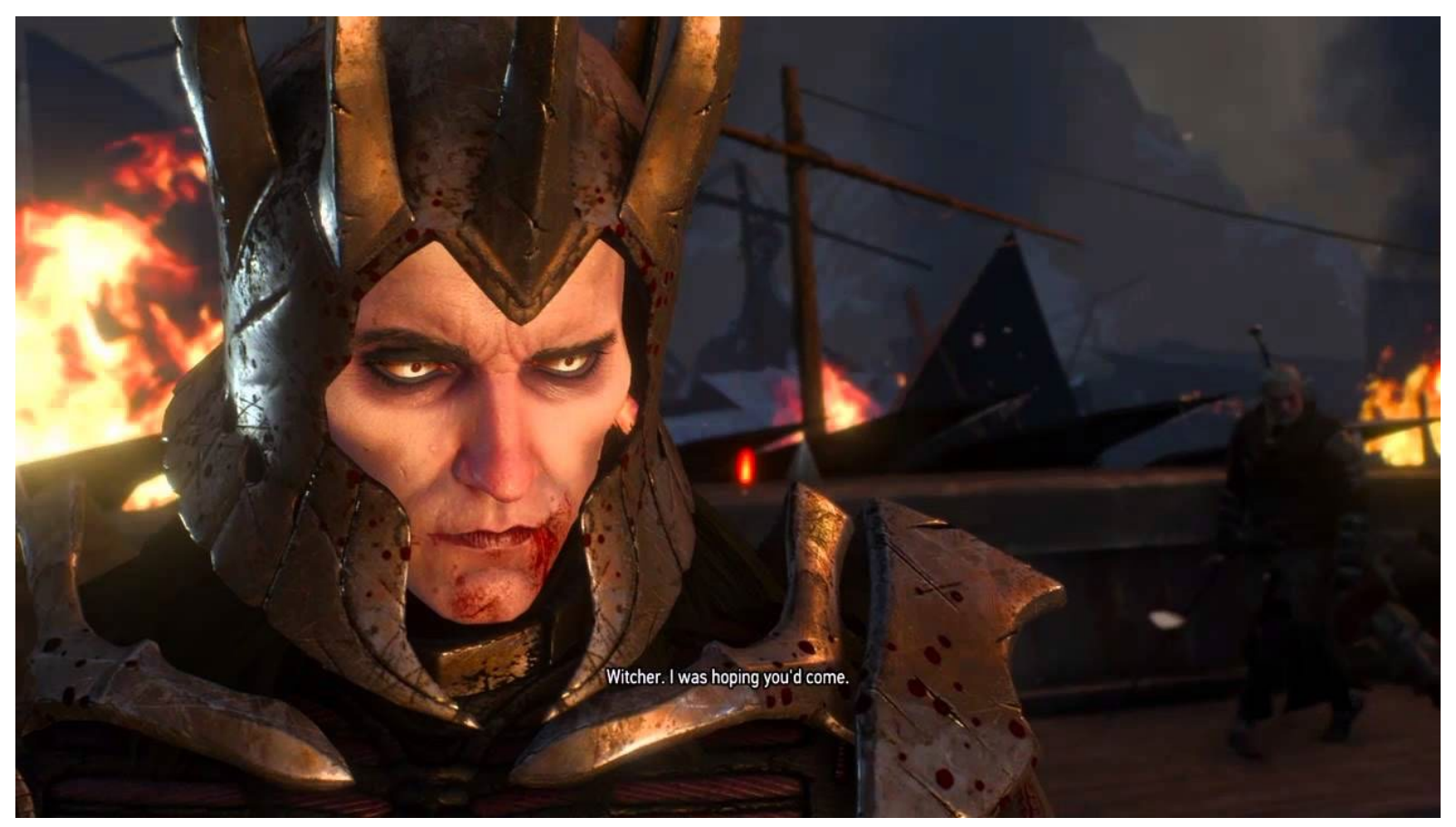

Figure 5: Eredin, King of the Wild Hunt C CD PROJEKT S.A.

The accent which has been chosen for the Nilfgaardians is Dutch/Germanic, which like Skellige is again grounded in the inspiration for their language. While loanwords from many languages are present in Nilfgaardian, Dutch is the foremost of these and as confirmed by the narrative designer of CD Projekt Red, who stated that the "Nilfgaardian used in their games is a mix of Elder Speech and Dutch" (Tomaszkiewicz 2017). And while strictly Germanic stereotypes of conquest might be applicable here, CD Projekt Red seems to have focused more heavily on the Dutch accent, as it is seldomly used in video games, but also does not carry many negative connotations. While TW3 does 
run the risk of reinforcing stereotypes, it presents an idealized standard version of language, thus indirectly implying that any dialect or accent within the game world is as valid as the next.

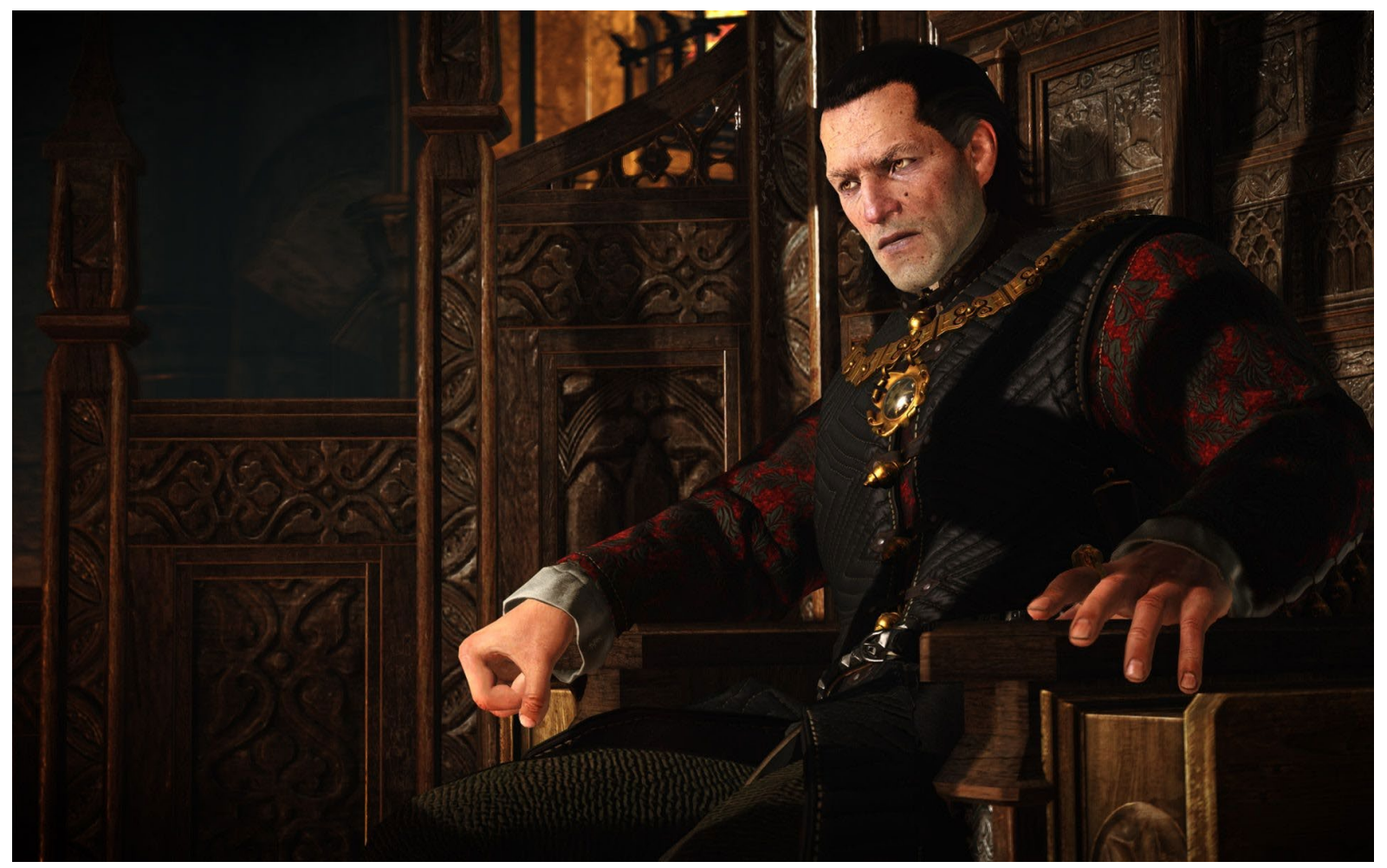

Figure 6: Charles Dance as Emhyr var Emreis C CD PROJEKT S.A

Finally, there was the interesting choice to have Geralt speak General American, as do the other witchers in the game. In Geralt's case this accent is marked by his rhotic /r/ in words like Witcher and answer (Mattsson 2018, 15), and the fact that there is no / $\mathrm{j} /$ in Geralt's pronunciation after / $\mathrm{d} / \mathrm{in}$ during (Wells 2013). The use of GA for a protagonist could be part of marketing strategy, as the accent might be more appealing and familiar to the large American gaming market, who can reflect themselves in a speaker of GA, rather than a British or non-standard variety of English. In the story it also helps to denote Geralt as being apart from the rest of humanity, as witchers are often stigmatized, and considered mutants that are not humans. Anders Bratteli also describes the GA accent "as a neutral way of marking otherness" (Bratteli 2011, 107). Besides the "GA dialect, with the lack of any regional linguistic features, appears more neutral than most ... making Geralt use this dialect could put emphasis on him as a neutral character" (Mattsson 2018, 16). This makes sense, since neutrality is the main political standpoint a witcher should possess, their only concern being hunting monsters, no matter who pays. Geralt himself displays no specific negative stereotypes, as he is a reliable hero, equal 
parts smart, and skilled in combat, with a caring nature for his friends and found family. In the end, GA is entirely distinct from British English and its varieties found in $T W 3$, further showing that their strategy for language distribution, was mainly about characterization and distinction.

\section{Discrimination in video games}

When it comes to $T W 3$ in most cases, the developers played to stereotypes to help flesh out and characterize NPCs in the world. Our real-world associations can help us shape an idea of the characters we meet when we hear their voices, and can immediately give us clues about the circumstances of region and social level the characters inhibits, even while knowing nothing of the world. Yet, all this has been achieved on the grounds of linguistic profiling, and can it consequentially be justified? If people might disassociate from the fiction, and not know about the stereotypes they would perhaps just help reinforce them, due to the lack of knowledge of the player, so the case of stereotyping seems inevitable. One would hope that players might just enjoy the presence of many different accents and dialects of English, but as exemplified by the quote from a message board below, this cannot be said to be the general case:

In Britain we still discriminate based upon accents, somebody with a broad Lancastrian/Yorkshire/Black Country accent is seen as dense, honest and humerous [sic], no matter how they look or dress or how much intelligence they have. Cockneys are seen as liars/wideboys, the West country jovial inbreeders, Highland Scots and parts of Ireland as romantic/poetic/lyrical drunks, People from Edinburgh as single malt sophisticates, those from Glasgow drink turps [sic] and fight their wives/ children and neighbours for sport (Salaciousbcrumb 2015).

While this sort of heavy stereotyping hopefully does not hold true for everyone, it can be hard to see past an accent, if you recognize it and begin to draw conclusions based purely on stereotypes. This is also reflected in the fact that the "study of language attitudes confirms that people judge personality traits and levels of professional competency on a speaker's accent" (Lien 2016, 9). As Lien herself also supports the notion that accents are efficient in characterization, she also claims that it is important to be aware of the effect they have, as they "can contribute to systematic stereotyping between certain parts of the population and specific characteristics, one should not underestimate the role sociolinguistic factors play in the media-oriented world we live in today" (Lien 2016, 47). 
While I would argue that the developers of $T W 3$ have sought to characterize and use accents in the least offensive way possible, they cannot escape the stereotypes they are playing into, while trying to create a realistic world with social hierarchy and regionalism. Can one portray as expansive a game as this without falling back to easy characterization by means of stereotyping? I would argue no, but I would commend the developers for distributing and developing a world with the internal linguistic logic it has, while it may at the same time come across as discriminating. Yet, as Bratteli puts: "It is easy to imagine that the game developer would feel that a barmaid speaking like a 'Southern belle' would crush the illusion of being at a traveller's inn in a medieval fantasy setting" (2011, 97). While playing to these stereotypes in their development of the game, they also make sense in their comparison with real-life accents as that of West Country, making us more immersed in the game. Therefore we must also be critical in our playing of video games, as the stereotypes might be harder to identify, as we are working on voice alone (Mattsson 2018, 22), and might not be aware of certain stereotypes being reinforced through this medium.

\section{Conclusion}

It seems then that linguistic profiling is necessary in the creation of a video game such as The Witcher 3: Wild Hunt. Without it, players might feel lost in a world as grand as this, and it also helps the developers in characterizing and distinguishing these NPCs to make them more memorable. This in turn helps to propel the game's fiction along, while providing the necessary information for players to consume. At the same time, however useful a tool linguistic profiling is, it also perpetuates discrimination as these linguistic profiles are more often than not based or reminds players of realworld stereotypes. This has also been done to portray authenticity within the game, but it does not, however, excuse the portrayal of Cockney-speakers as criminals. Yet, while The Witcher 3 does play on popular stereotypes in some areas, it is also diversified enough to portray different regions with accents without necessarily discriminating, as seen with Skellige and the general distribution of accents between the four dominant Northern Kingdoms, of Aedirn, Temeria, Kaedwen and Redania. The accents have been allocated as logically as possible, and while stereotypes might appear in the real world, The Witcher 3 does not necessarily ask us to judge any race or character as being worse than another. Most are just various shades of gray, so if anyone is stereotyping is it not us? 


\section{Reference list}

Baugh, John. 2003. "Linguistic Profiling." In Black Linguistics: Language, Society and Politics in Africa and the Americas, edited by Sinfree Makoni, Geneva Smitherman, Arnetha F. Ball and Arthur K. Spears, 155-168. New York: Routledge.

—. 2016. "Linguistic Profiling and Discrimination." In The Oxford Handbook of Language and Society, edited by Ofelia García, Nelson Flores, and Massimiliano Spotti, 349-368. New York: Oxford University Press.

Bratteli, Anders. 2011 "World of Speechcraft: Accent Use and Stereotyping in Computer Games." MA Thesis, University of Bergen.

https://pdfs.semanticscholar.org/c063/d8dfca1e6c97fdf0993c053405e5f3241dbe.pdf?_ga=2.999 86841.626081321.1589956808-79048817.1589956808

Campbell-Howes, Kirsten. 2019. "10 Scottish Phrases (\& How to Use Them).” Busun Blog, April 29, 2019. https://blog.busuu.com/scottish-expressions/. Accessed May 27, 2020.

Castelow, Ellen. n.d. “Yorkshire Dialect.” Historic UK. https://www.historicuk.com/CultureUK/Yorkshire-Dialect/. Accessed May 26, 2020.

Coupland, Nikolas, and Hywel Bishop. 2007. "Ideologised Values for British Accents 1." Journal of Sociolinguistics 11, no. 1 (February): 74-93. https://doi.org/10.1111/j.1467-9841.2007.00311.x.

CD Projekt Red. 2015. The Witcher 3: Wild Hunt. Published by CD Projekt.

Hellström, Eugen. 2019. “A Lack of Flæ:r: A Comparative Study of English Accent Stereotypes in Fantasy Role-Playing Games.” BA thesis, Jönköping University. http:/ www.divaportal.org/smash/get/diva2:1349628/FULLTEXT01.pdf.

Lippi-Green, Rosina. 2012. “Chapter 7: Teaching Children How to Discriminate (What We Learn from the Big Bad Wolf)." In English with an Accent Language: Ideology and Discrimination in the United States, 2nd ed., 101-127. London: Routledge.

Lien, Yngvild Audestad. 2016. "Game of Thrones: A Game of Accents? A Sociolinguistic Study of the Representation of Accents in HBO's Television Series.” MA thesis, Norwegian University of Science and Technology. https://ntnuopen.ntnu.no/ntnuxmlui/bitstream/handle/11250/2403673/Masteroppgave\%20$\% 20$ Lien.pdf?sequence $=1 \&$ is Allowed $=y$.

Mattsson, Emil. 2018. "Dialect representation: Language varieties in The Witcher 3: Wild Hunt.” BA thesis, University West. http://www.divaportal.org/smash/get/diva2:1267450/FULLTEXT01.pdf. 
Noclip. 11 Oct. 2017. "Translating \& Adapting The Witcher." YouTube, commentary by Danny O’Dwyer. https://www.youtube.com/watch?v=Gxg5INjNopo. Accessed April 19, 2020.

Nour, Lena. 2019. "Understanding Linguistic Discrimination: Consequences and Policy Responses." Policy Perspectives, January 31, 2019. https:/ / policy-perspectives.org/2019/01/31/understandinglinguistic-discrimination-consequences-and-policy-responses/. Accessed May 19, 2020.

Purnell, Thomas, William Idsardi, and John Baugh. "Perceptual and Phonetic Experiments on American English Dialect Identification.” Journal of Language and Social Psychology 18, no. 1 (1999): 10-30. https://doi.org/10.1177/0261927x99018001002.

Robinson, Jonnie. 2019. “Accents and Dialects of Northern Ireland.” British Library, April 24, 2019. https://www.bl.uk/british-accents-and-dialects/articles/accents-and-dialects-of-northern-ireland. Accessed May 27, 2020.

Salaciousbcrumb. December 25, 2015. Comment \#16 on Cadmun, "What do you call this fucking annoying accent?" https://rpgcodex.net/forums/index.php?threads/what-do-you-call-thisfucking-annoying-accent.105301/. Accessed May 25, 2020.

Tomaszkiewicz, Mateusz. 2017. Twitter, December 5, 2017. https://mobile.twitter.com/MTomaszkiewicz/status/938010674889986048. Accessed May 27, 2020.

Wells, John C. 2013. “Accents of English.” UCL Phonetics and Linguistics, last revised September 28, 2013. https://www.phon.ucl.ac.uk/home/wells/accentsanddialects/. Accessed May 26, 2020. Witcher Wiki. n.d. “Skellige” Retrieved May 27, 2020. https://witcher.fandom.com/wiki/Skellige. 